Keywords: Environmental, Groundwater, Contamination, NPDES

Retention: Permanent

\title{
Sustainable Remediation Software Tool Exercise and Evaluation
}

\author{
Joel L. Kohn \\ Ralph L. Nichols \\ Brian B. Looney
}

June 2011

Sponsored by the U.S. Department of Energy Environmental Management Office of Groundwater and Soil Cleanup (EM-32) and the DOE Center for Sustainable Groundwater and Soil Solutions
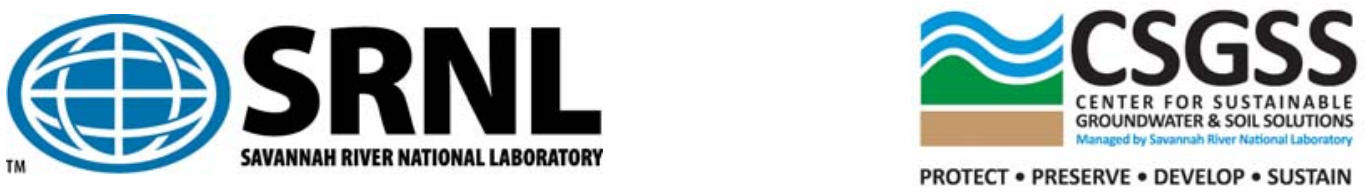

Prepared for the U.S. Department of Energy under contract number DE-AC09-08SR22470. 
SRNL-STI-2011-00288

Revision 0

\section{DISCLAIMER}

This work was prepared under an agreement with and funded by the U.S. Government. Neither the U.S. Government or its employees, nor any of its contractors, subcontractors or their employees, makes any express or implied:

1. warranty or assumes any legal liability for the accuracy, completeness, or for the use or results of such use of any information, product, or process disclosed; or

2. representation that such use or results of such use would not infringe privately owned rights; or

3. endorsement or recommendation of any specifically identified commercial product, process, or service.

Any views and opinions of authors expressed in this work do not necessarily state or reflect those of the United States Government, or its contractors, or subcontractors.

\section{Printed in the United States of America \\ Prepared for \\ U.S. Department of Energy}




\section{EXECUTIVE SUMMARY}

The goal of this study was to examine two different software tools designed to account for the environmental impacts of remediation projects. Three case studies from the Savannah River Site (SRS) near Aiken, SC were used to exercise SiteWise (SW) and Sustainable Remediation Tool (SRT) by including both traditional and novel remediation techniques, contaminants, and contaminated media. This study combined retrospective analysis of implemented projects with prospective analysis of options that were not implemented. Input data were derived from engineering plans, project reports, and planning documents with a few factors supplied from calculations based on Life Cycle Assessment (LCA). Conclusions drawn from software output were generally consistent within a tool; both tools identified the same remediation options as the "best" for a given site. Magnitudes of impacts varied between the two tools, and it was not always possible to identify the source of the disagreement. The tools differed in their quantitative approaches: SRT based impacts on specific contaminants, media, and site geometry and modeled contaminant removal. SW based impacts on processes and equipment instead of chemical modeling. While SW was able to handle greater variety in remediation scenarios, it did not include a measure of the effectiveness of the scenario. 


\section{TABLE OF CONTENTS}

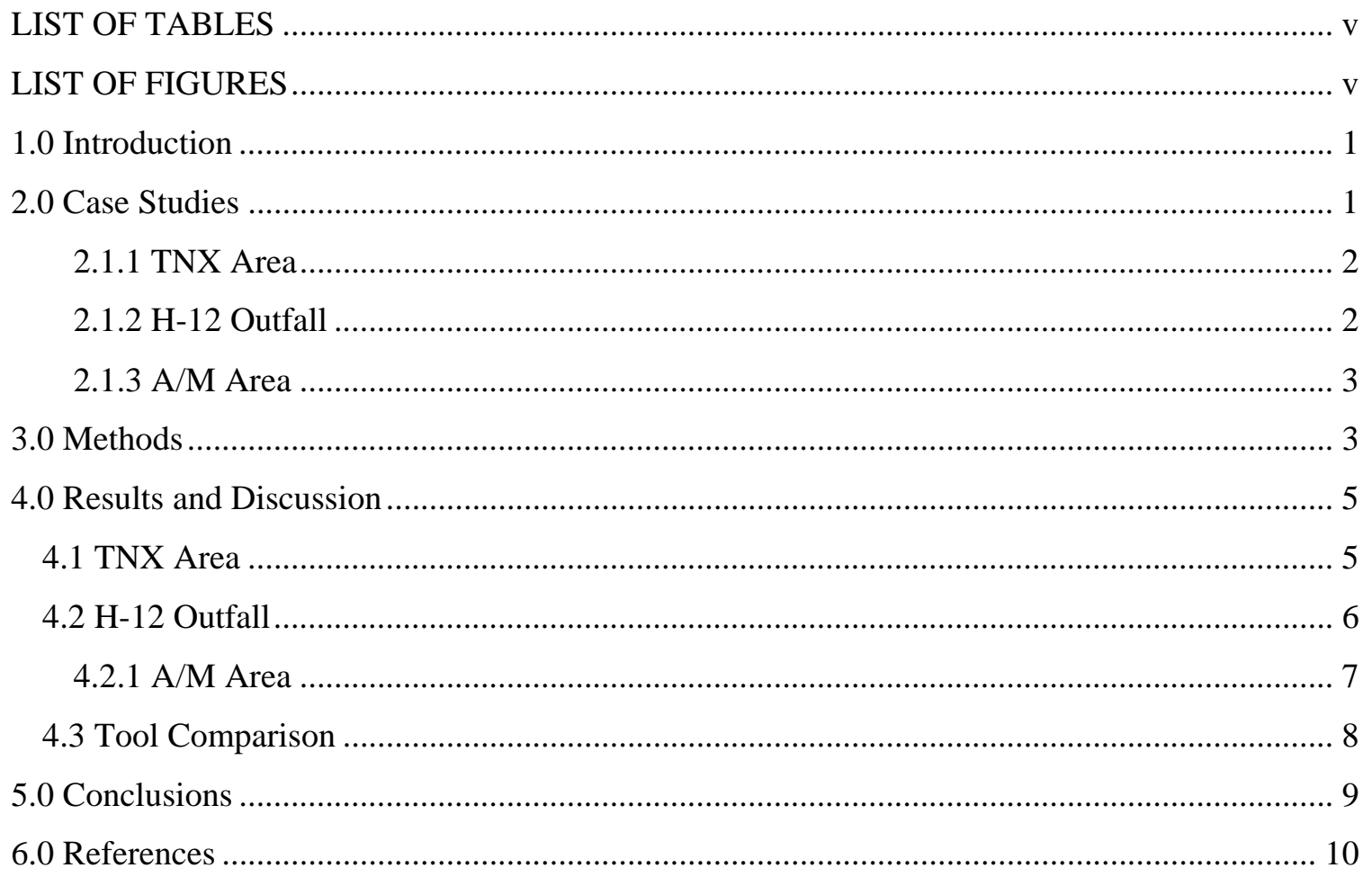




\section{LIST OF TABLES}

Table 1 Selected input data and output values from SW and SRT for three case studies. 4

\section{LIST OF FIGURES}

Figure 1 Selected impact category results for TNX area. Note multiple scales............................. 5

Figure 2 H-12 outfall energy consumption results from SRT broken down by operative phase and activity. Note different scales............................................................................................ 6

Figure 3. Energy consumption results for SW for A/M Area. Note different scales for SnCl2 and Reinjection. 


\section{LIST OF ABBREVIATIONS}

$\begin{array}{ll}\text { SRNL } & \text { Savannah River National Laboratory } \\ \text { DOE } & \text { Us Department of Energy } \\ \text { SRI } & \text { Sustainable Remediation Initiative } \\ \text { CVOC } & \text { Chlorinated Volatile Organic Compound } \\ \text { SW } & \text { SiteWise, Final May 2010 } \\ \text { SRT } & \text { Sustainable Remediation Tool, Rev. 2 December } 2009 \\ \text { SRS } & \text { Savannah River Site } \\ \text { LCA } & \text { Life Cycle Assessment } \\ \text { GHG } & \text { Green House Gas } \\ \text { NOx } & \text { Oxides of Nitrogen } \\ \text { SOx } & \text { Oxides of Sulfur } \\ \text { PM10 } & \text { Coarse Particulate Matter }\end{array}$




\subsection{Introduction}

There is a growing awareness of the importance of sustainable solutions for continued human existence. It is within this awareness that the Center for Sustainable Groundwater and Soil Solutions within the Savannah River National Laboratory (SRNL) and the larger U.S. Department of Energy (DOE) created the Sustainable Remediation Initiative (SRI) (Nichols, 2010) to advance the acceptance and incorporation of green and sustainable remediation metrics into the larger body of remedial work. A further goal of the SRI is to increase awareness of the availability of novel remediation techniques and tools. Specifically the SRI aims to achieve the best possible environmental quality by focusing on four goal categories: mitigating damages, maximizing environmental services, minimizing remediation resource footprint, and managing risks.

Expanding the scope of remediation projects beyond the traditional emphasis on simply mitigating damages makes the selection of the "best" alternative more complicated. Software tools can thus play an important role in the identification and selection of the ideal remediation technology for a given project. To this end, sustainable remediation software tools are available to treat the remediation process with a method similar to Life Cycle Assessment by considering environmental impacts from different phases of a remediation project. These tools take into account the energy inputs and emission outputs associated with manufacturing materials and chemicals, construction processes, and continued operation and maintenance of the remediation project.

This project focuses on two existing software tools designed to approach sustainable remediation. The tools themselves are both based on the Microsoft Excel spreadsheet application and use macros to calculate impacts from user input and impact factors contained within the spreadsheet. SiteWise (SW) was developed by Battelle, the U.S. Navy, and the U.S. Army Corps of Engineers. Sustainable Remediation Tool (SRT) was developed by the U.S. Air Force Center for Engineering and the Environment. They are both designed to be implemented in the planning stages of a project to estimate the environmental impacts of that project using different treatment technologies.

It is the goal of this study to exercise and evaluate two existing sustainable remediation software packages: SW and SRT by using three case studies of completed and ongoing remediation projects on the Savannah River Site (SRS). The case studies selected provide a range of contaminants and polluted media with which to test the tools. The main focus is the applicability and adaptability of the software to different remediation techniques.

\subsection{Case Studies}

SRS, near Aiken, SC, offers a unique opportunity to study sustainable approaches to remediation with a variety of remediation efforts, documented procedures, and a mix of traditional and innovative treatment regimens. The three case studies selected to exercise SW and SRT are:

- TNX area - chlorinated volatile organic compound (CVOC) contamination in groundwater and soil

- H-12 outfall - copper contamination in surface water

- A/M area - mercury contamination in groundwater. 
These particular sites offer traditional techniques like pump-and-treat with air stripping and novel techniques like the addition of a humate solution to detoxify metals.

\subsubsection{TNX Area}

TNX area was the site of pilot-scale testing of chemical processes to be used elsewhere on SRS. Non-radioactive waste was disposed in unlined basins which resulted in the contamination of the vadose zone and shallow groundwater with CVOCs. To treat the contaminants, a pumpand-treat system with air stripping was used for 10 years to immobilize the contaminant plume, while soil vapor extraction was used for a year to treat the source in the soil. The pump-and-treat system was followed by treatment with edible oil pumped into the aquifer as a final treatment to stimulate microbial activity to further degrade the CVOCs in the groundwater.

The TNX project represents the most traditional remediation scenario of the selected case studies in that the pollutant and the contaminated media are commonly addressed in remediation scenarios. The specifics of the site and contamination were available from engineering drawings, well diagrams, and reports and were used as input data for the two software packages. (Riha 2006, 2009, 2010, Noonkester 2005).

\subsubsection{H-12 Outfall}

The H-12 outfall serves as a discharge point for process water and surface runoff associated with H-Area of SRS. This discharge is in governed by a National Pollutant Discharge Elimination System (NPDES) permit that regulates the copper and zinc concentrations to $6 \mathrm{ppb}$ and $100 \mathrm{ppb}$ respectively. The copper concentration could not consistently meet the NPDES limit without treatment. The copper in this surface water can be attributed to copper components in plumbing and pumps, natural levels in groundwater withdrawn for processes, and storm water flow over impervious surfaces.

To bring this outfall into compliance with the NPDES permit, a variety of options were subjected to a feasibility study to identify cost effective treatments that would effectively mitigate the damage. The study identified peat beds as the best treatment technology beating out ion exchange, constructed wetland treatment, and water re-routing without treatment. Using a peat bed as a natural ion-exchange resin would have been a novel approach; however, before this treatment plan was implemented, another non-traditional option was identified: the injection of humate solution-naturally occurring organic matter-into the surface water to detoxify the copper rather than to remove it from the stream. The humate system was installed and consists of two 5500 gallon storage tanks for the liquid humate solution, pumps, a computer controller, and piping. The system is actively monitored, with sensors in the stream relaying information to the computer which regulates the metering pumps based on stream flow and $\mathrm{pH}$.

This case study is an exercise in adapting the software packages to non-traditional treatment alternatives. Both the peat bed system and the humate injection system fit that description, and since the peat bed system was fully engineered before the humate system was identified, both systems have engineering drawings available for project details to serve as input data for the software. The contaminant and medium are also outside the realm of what is traditionally considered remediation and is more in-line with wastewater treatment, further pushing the capabilities of the software. (Looney and Millings 2009, Halverson et al. 2010, Millings et al. 2009, WRSC 2007) 


\subsubsection{A/M Area}

In 1981 an air stripper tower was installed in A/M area to treat groundwater contaminated with CVOCs. This tower processes approximately $500 \mathrm{gpm}$ and the resulting water is discharged to an outfall for surface water. This discharge contains mercury at an average concentration of approximately $250 \mathrm{ng} / \mathrm{L}$. While this is below drinking water standards (2000 ng/L, typical) it exceeds surface water protection standards which typically fall in the range of 1-50 ng/L total mercury which are designed to prevent bioaccumulation in fish. To address the mercury problem a stannous chloride solution injection system was installed upstream of the air stripper. The stannous chloride solution reduces the mercury to its elemental form which can subsequently be removed by the air stripper, leaving the effluent from the process with a total mercury concentration of less than $10 \mathrm{ng} / \mathrm{L}$. The focus of this case study is the mercury contamination only, as size of the CVOC plume and the multiple treatment technologies applied over multiple decades inhibit their input into the software. (Looney et al. 2001, Looney et al. 2010)

Since the effluent of the air stripper without the stannous chloride treatment is within drinking water standards, another potential solution would be to inject the water back into the aquifer. This solution would require pumps and wells to distribute the water. This case study again pushes the software packages beyond the realm of traditional remediation with the contaminant and treatment technologies.

\subsection{Methods}

The software packages SiteWise and Sustainable Remediation Tool-Tier 2 were used to estimate the environmental impacts associated with a particular remediation project. The results were based on input data supplied by the user and on software-specific calculations to translate the quantities of materials, use of equipment and vehicles, and use of energy into impacts. Both SW and SRT require similar, but not identical inputs. These differences and their implications will be described further in the Results and Discussion section.

Input data were primarily derived from site reports and engineering drawings detailing the construction and operation of the various remediation operations. These included lengths and materials for pipes and wells, earth volumes for trenching, excavation, and other earthworks, and quantities of other materials for construction; times and schedules for investigation; treatment schedules, pumping rates and volumes, and visits by workers for operations; and follow-up monitoring schedules. Details of contaminant plume geometry and concentrations were also taken from site reports. Each active treatment required daily monitoring to ensure equipment operation. These data, where relevant, were entered into SRT and SW to generate the environmental impact for several categories: greenhouse gas (GHG) emissions, Energy consumption, water use, oxides of nitrogen (NOx) emissions, oxides of sulfur ( $\mathrm{SOx}$ ) emissions, coarse particulate matter $\left(\mathrm{PM}_{10}\right)$ emissions, fatality risk, accident risk, lost work hours and technology cost. Table 1 shows selected input and output from the two software packages. 
Table 1 Selected input data and output values from SW and SRT for three case studies.

\begin{tabular}{|c|c|c|c|c|c|c|c|c|}
\hline & \multicolumn{4}{|c|}{ TNX Area } & \multicolumn{2}{|c|}{ H-12 NPDES Outfall } & \multicolumn{2}{|c|}{ A/M Area } \\
\hline & $\begin{array}{l}\text { Soil Vapor } \\
\text { Extraction }\end{array}$ & Excavation & $\begin{array}{l}\text { Pump \& } \\
\text { Treat }\end{array}$ & Oil Injection & Humate Injection & Peat Beds & $\mathrm{SnCl}_{2}$ & Reinjection \\
\hline $\begin{array}{l}\text { Quantity of media } \\
\text { treated }\end{array}$ & \multicolumn{2}{|c|}{$23,500 \mathrm{~m}^{3}$ soil } & \multicolumn{2}{|c|}{$\begin{array}{c}\text { 3.50 E8 gal (1.32 E9 L) } \\
\text { groundwater }\end{array}$} & \multicolumn{2}{|c|}{$\begin{array}{c}1.10 \text { E10 gal (4.18 E10 L) waste } \\
\text { water discharge }\end{array}$} & \multicolumn{2}{|c|}{$\begin{array}{c}2.63 \mathrm{E} 8 \mathrm{gal}(9.95 \mathrm{E} 8 \mathrm{~L}) \\
\text { groundwaer }\end{array}$} \\
\hline $\begin{array}{ll}\text { Quantity } & \text { of } \\
\text { contaminant } & \text { of } \\
\text { treated } & \end{array}$ & \multicolumn{2}{|c|}{$1.88 \mathrm{~kg} \mathrm{CVOCs}$} & \multicolumn{2}{|c|}{$66.1 \mathrm{~kg}$ CVOCs } & \multicolumn{2}{|c|}{320 kg copper } & \multicolumn{2}{|c|}{$249 \mathrm{~g}$ mercury } \\
\hline $\begin{array}{ll}\text { Time } & \text { frame } \\
\text { analyzed } & \end{array}$ & $1 \mathrm{yr}$ & na & $\begin{array}{l}10 \mathrm{yr}(95 \% \\
\text { operation) }\end{array}$ & $5 \mathrm{yr}$ & $30 \mathrm{yr}$ & $30 \mathrm{yr}$ & $1 \mathrm{yr}$ & $1 \mathrm{yr}$ \\
\hline $\begin{array}{l}\text { Primary equipment/ } \\
\text { components }\end{array}$ & $\begin{array}{l}1 \times 15 h p \\
\text { pump }\end{array}$ & $\begin{array}{l}23,500 \mathrm{~m}^{3} \\
\text { removed } \\
\text { and } \\
\text { backfilled }\end{array}$ & $\begin{array}{l}4 x \text { 3hp gw } \\
\text { pumps, one } \\
\text { air stripper } \\
\text { ( } 2 \times 5 h p \\
\text { blower) }\end{array}$ & $\begin{array}{c}1 \times \text { high head } \\
\text { pump } \\
\text { variable rate, } \\
5.30 \mathrm{E} 4 \mathrm{lb} \\
(2.40 \mathrm{E} 4 \mathrm{~kg}) \\
\text { oil }\end{array}$ & $\begin{array}{l}\text { 1x .75hp, } 2 \times 3 \\
\text { hp pumps } 4.68 \\
\text { E6 gal (1.77 E7 } \\
\text { L) Humate used }\end{array}$ & $\begin{array}{l}\text { 4x } 813 \mathrm{gpm} \\
20 \mathrm{ft} \text { head } \\
\text { Pump, } \\
5.55 \mathrm{E} 6 \mathrm{~kg} \\
\text { peat used }\end{array}$ & $\begin{array}{c}1 \mathrm{x} \\
2.48 \mathrm{E}-4 \\
\text { gpm } \\
10 \mathrm{ft} \\
\text { head } \\
\text { pump }\end{array}$ & $\begin{array}{c}\text { 1x } 500 \mathrm{gpm} \\
100 f t \text { head } \\
\text { pump }\end{array}$ \\
\hline $\begin{array}{l}\text { Energy } \\
\text { Consumption, MJ } \\
\text { (SWISRT) }\end{array}$ & $\begin{array}{l}11.1 \mathrm{E} 5 / \\
3.9 \mathrm{E} 5\end{array}$ & $\begin{array}{l}2.58 \mathrm{E} 6 / \\
5.10 \mathrm{E} 6\end{array}$ & $\begin{array}{l}16.0 \mathrm{E} 6 / \\
7.70 \mathrm{E} 6\end{array}$ & $\begin{array}{l}2.53 \mathrm{E} 5 / \\
0.270 \mathrm{E} 5\end{array}$ & 18.5 E6 / na & 19.4 E6 / na & $\begin{array}{l}\text { 1.14 E4 } \\
\text { / na }\end{array}$ & $\begin{array}{c}2.05 \mathrm{E} 6 / \\
\mathrm{na}\end{array}$ \\
\hline $\begin{array}{l}\text { Greenhouse gass } \\
\text { emmissions, metric } \\
\text { ton (SWISRT) }\end{array}$ & $69.3 / 24.5$ & $140 / 354$ & $1020 / 426$ & $11.0 / 66.2$ & $1,140 / \mathrm{na}$ & $1,120 / \mathrm{na}$ & $\begin{array}{c}0.944 / \\
\text { na }\end{array}$ & $128 / \mathrm{na}$ \\
\hline $\begin{array}{l}\text { NOx metric ton } \\
\text { (SWISRT) }\end{array}$ & $\begin{array}{l}9.75 \mathrm{E}-2 / \\
13.6 \mathrm{E}-2\end{array}$ & $\begin{array}{c}0.347 / \\
2.81\end{array}$ & $1.71 / 2.54$ & $\begin{array}{l}3.94 \mathrm{E}-3 / \\
14.5 \mathrm{E}-3\end{array}$ & $1.28 / \mathrm{na}$ & $1.20 / \mathrm{na}$ & $\begin{array}{l}6.29 \mathrm{E}-4 \\
/ \mathrm{na}\end{array}$ & $0.221 / \mathrm{na}$ \\
\hline $\begin{array}{l}\text { SOx metric ton } \\
\text { (SWISRT) }\end{array}$ & $0.396 / 0.227$ & $\begin{array}{c}8.48 \mathrm{E}-2 \text { / } \\
0.0272 \mathrm{E}-2\end{array}$ & $5.33 / 4.72$ & $\begin{array}{l}14.3 \mathrm{E}-3 / \\
4.08 \mathrm{E}-3\end{array}$ & $5.34 / \mathrm{na}$ & $3.29 / \mathrm{na}$ & $\begin{array}{l}1.99 \mathrm{E}-4 \\
\text { / na }\end{array}$ & $0.663 / \mathrm{na}$ \\
\hline $\begin{array}{l}\mathrm{PM}_{10} \text { metric ton } \\
(\mathrm{SWISRT})\end{array}$ & $\begin{array}{l}5.38 \mathrm{E}-4 / \\
408 \mathrm{E}-4\end{array}$ & $\begin{array}{l}3.55 \mathrm{E}-2 / \\
136 . \mathrm{E}-2\end{array}$ & $\begin{array}{c}0.0382 \text { l } \\
0.880\end{array}$ & $\begin{array}{l}18.1 \mathrm{E}-4 / \\
7.26 \mathrm{E}-4\end{array}$ & 6.17 E-3 / na & 4.54 E-2 / na & $\begin{array}{l}1.34 \mathrm{E}-4 \\
\text { / na }\end{array}$ & $\begin{array}{l}5.45 \mathrm{E}-3 / \\
\mathrm{na}\end{array}$ \\
\hline Injury Risk & $\begin{array}{l}5.21 \mathrm{E}-3 / \\
1.60 \mathrm{E}-3\end{array}$ & $\begin{array}{c}0.0399 / \\
0.200\end{array}$ & $\begin{array}{l}3.60 \mathrm{E}-2 / \\
1.40 \mathrm{E}-2\end{array}$ & $\begin{array}{l}5.57 \mathrm{E}-4 / \\
4.20 \mathrm{E}-4\end{array}$ & $2.24 \mathrm{E}-2$ / na & 7.70 E-2 / na & $\begin{array}{l}1.83 \mathrm{E}-3 \\
/ \text { na }\end{array}$ & $\begin{array}{l}1.67 \mathrm{E}-2 / \\
\mathrm{na}\end{array}$ \\
\hline
\end{tabular}




\subsection{Results and Discussion}

The results of SW are a series of bar-charts based on the output of each remediation option for each impact category and are also subdivided into impacts associated with each phase of each project. There is one chart for each impact category: greenhouse gas (GHG) emissions, energy consumption, water impacts, $\mathrm{NO}_{\mathrm{x}}$ emissions, $\mathrm{SO}_{\mathrm{x}}$ emissions, coarse particulate matter $\left(\mathrm{PM}_{10}\right)$, risk of fatality, and risk of injury. These results are further subdivided into a page for each remediation alternative where each phase of the project-investigation, construction, operation, and long-term monitoring-is represented by a bar that is divided into sections based on the contribution to the total impact for the phase by five categories: consumables (materials), personnel transportation, equipment transportation, equipment use, and residual handling.

The results of SRT consist of a table of values of environmental impacts for several categories. The impact categories in SRT are carbon dioxide emissions, $\mathrm{NO}_{\mathrm{x}}$ emissions, $\mathrm{SO}_{\mathrm{x}}$ emissions, coarse particulate matter $\left(\mathrm{PM}_{10}\right)$, energy consumption, technology cost, safety/accident risk, and change in resource service.

\subsection{TNX Area}

Both SW and SRT were used to analyze soil and groundwater remediation actions for TNX. The actions analyzed for contaminated soil were soil vapor extraction and excavation. SVE consisted of one year of treatment followed by four years of continued monitoring. Excavation (not implemented) consisted of three months of excavating the contaminated soil, transporting it to a hazardous waste disposal unit, and transporting clean fill to the site. Figure 1 shows the results from selected impact categories from both

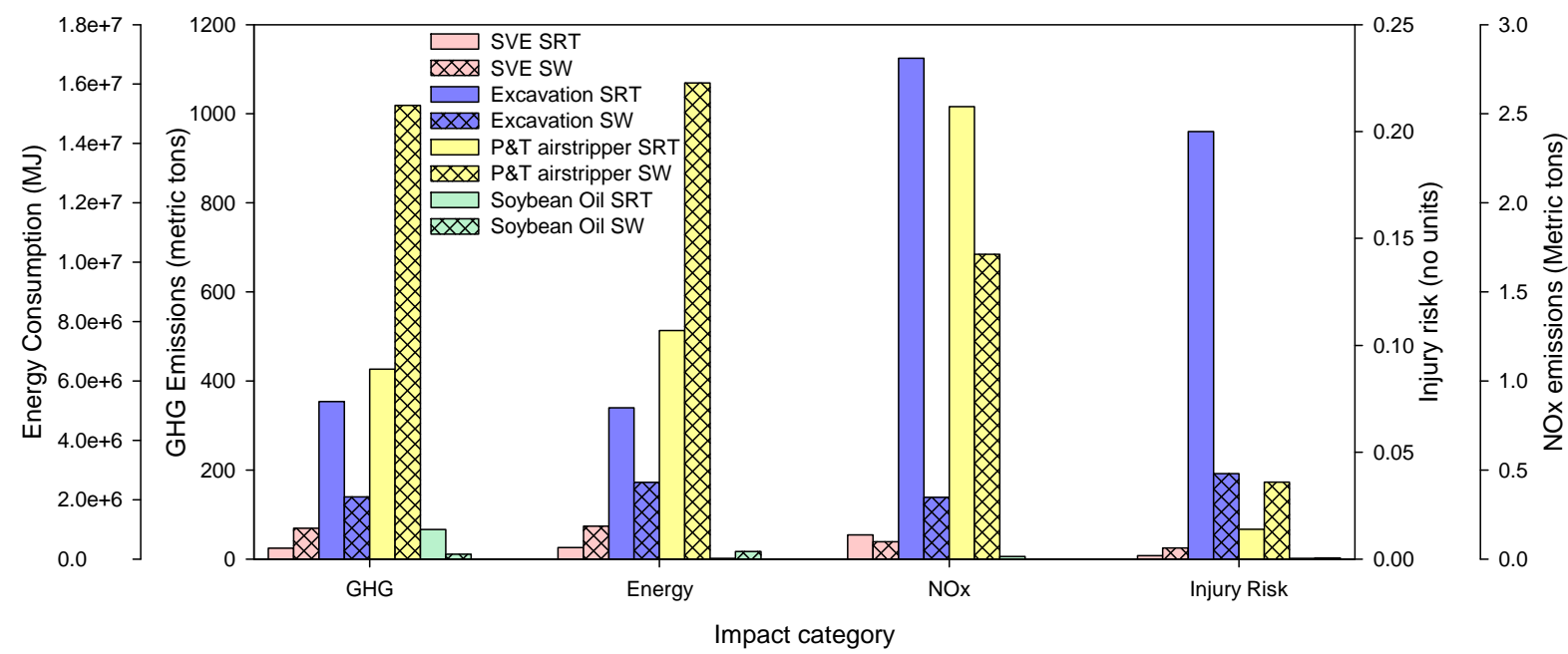

Figure 1 Selected impact category results for TNX area. Note multiple scales.

SRT and SW for the different remediation actions for both soil and groundwater at TNX.

Soil vapor extraction was determined to have lower greenhouse gas emissions, energy consumption, NOx emissions and injury risk than excavation by both SW and SRT. The groundwater remediation strategy was designed to contain the contaminated groundwater 
while a final action was identified. A pump and treat system with air stripping for containment was operated for ten years prior to the use of oil injection for mass removal in the heart of the contaminant plume. Long-term monitoring was included with the oil treatment in this analysis rather than with the pump-and-treat system. The oil injection included 60 days of oil injection spread over 1 year followed by 4 years of quarterly monitoring. Energy consumption and injury risk from SW were higher than SRT for both pump and treat and oil injection, while SRT had higher estimates than SW for NOx emissions in both scenarios.

\section{2 H-12 Outfall}

Peat beads and humate injection for meeting NPDES limits at the H12 Outfall were analyzed using SW only; the considered scenarios were incompatible with SRT input structure required, and meaningful results could not be coaxed from the software. SW breaks remediation actions into phases and the activities necessary to complete the phases. For purposes of this analysis the treatment time was assumed to be 30 years. Thirty years was chosen as a reasonable estimate of SRS operations in the area, and captures 6 replacement cycles of the peat cell system. Replacement every 5 years for the peat system was a conservative estimate based on preliminary reports and was designed to prevent accumulation of radioisotopes in the peat to a level which would require its disposal as a mixed waste. Figure 2 presents a breakdown of energy consumption by activity for both the construction and operation phase of both actions analyzed for H-12.

During construction of both alternatives consumables represent the largest energy demand while during operation equipment use dominated energy consumption.

The impacts for the humate system were dominated by the use of electric pumps to recirculate and inject the humate solution into the stream. These pumps run constantly, and even though they are controlled by a computer system, the required amendment volume is typically below the

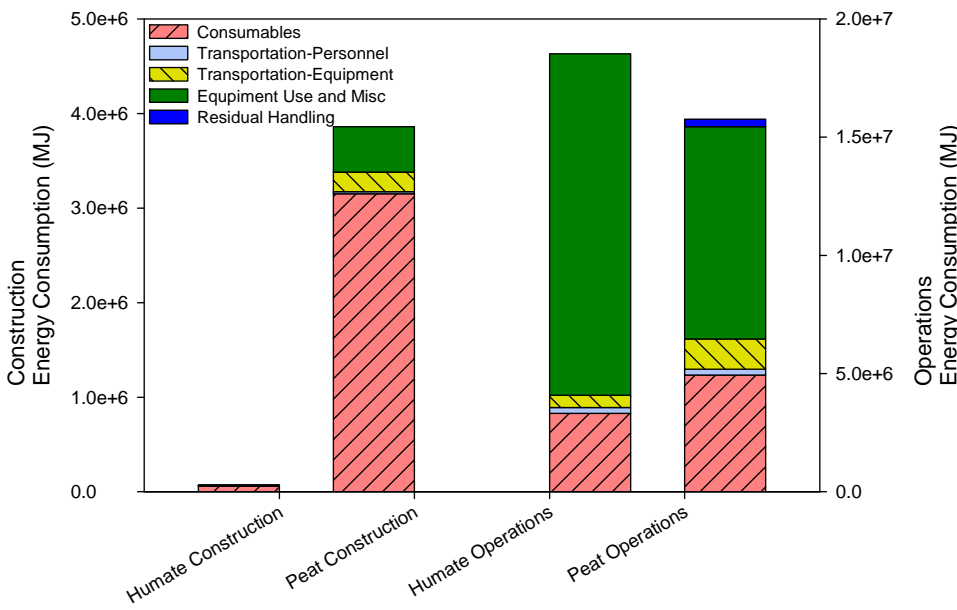

Figure 2 H-12 outfall energy consumption results from SRT broken down by operative phase and activity. Note different scales. minimum operational speed for the pumps.

SW does not incorporate the impact of clearing, grubbing, and disposition of waste from approximately three acres of woodland that would have been required for the construction of the peat beds, and these impacts were not manually estimated. The 
humate system did have significantly less construction associated with it, and this is partially reflected in the difference in the risk to the workers at this site.

Four other cases of the $\mathrm{H}-12$ site were modeled to examine the sensitivity of the results to several factors: doubling of humate manufacturing impacts, change of energy region from Georgia to South Carolina/North Carolina, and change of water chemistry from $\mathrm{pH} 6$ to $\mathrm{pH} 8$. The doubling of humate impacts was designed to account for the crude nature of the life cycle impact calculations for humate manufacture. The change of energy region was designed to examine the effects of a different mix of energy sources on the environmental impacts. The change of water chemistry would reduce the amount of humate needed to detoxify the copper in the stream according to the process control equation for the system (Looney and Millings 2009). The results from the sensitivity cases were not significantly different from the baseline cases.

\subsubsection{A/M Area}

The stannous chloride injection system and the reinjection well system were analyzed using SW only. As was the case with the H-12 outfall, the input data were incompatible with the structure of SRT, and no meaningful results could be generated with SRT. The treatment time for this case was one year as the project represents an additional treatment required to dispose of the water from the treatment of $\mathrm{A} / \mathrm{M}$ area groundwater for CVOCs.

The energy consumption during the construction phase for $\mathrm{SnCl}_{2}$ treatment was dominated by consumables, that is, the embodied energy in the materials used for the system. The reinjection construction was dominated by the use of equipment, mainly drilling the wells required to inject the effluent back into the aquifer. The operation phase for $\mathrm{SnCl}_{2}$ was dominated by transportation of personnel to ensure proper operation of equipment while the reinjection system's operational phase was dominated by the use of equipment: the pump required to push the water back into the aquifer. These results are illustrated in Figure 3. The complete results follow similar patterns to the energy consumption and indicate that the $\mathrm{SnCl}_{2}$ system is environmentally preferable to the reinjection system.

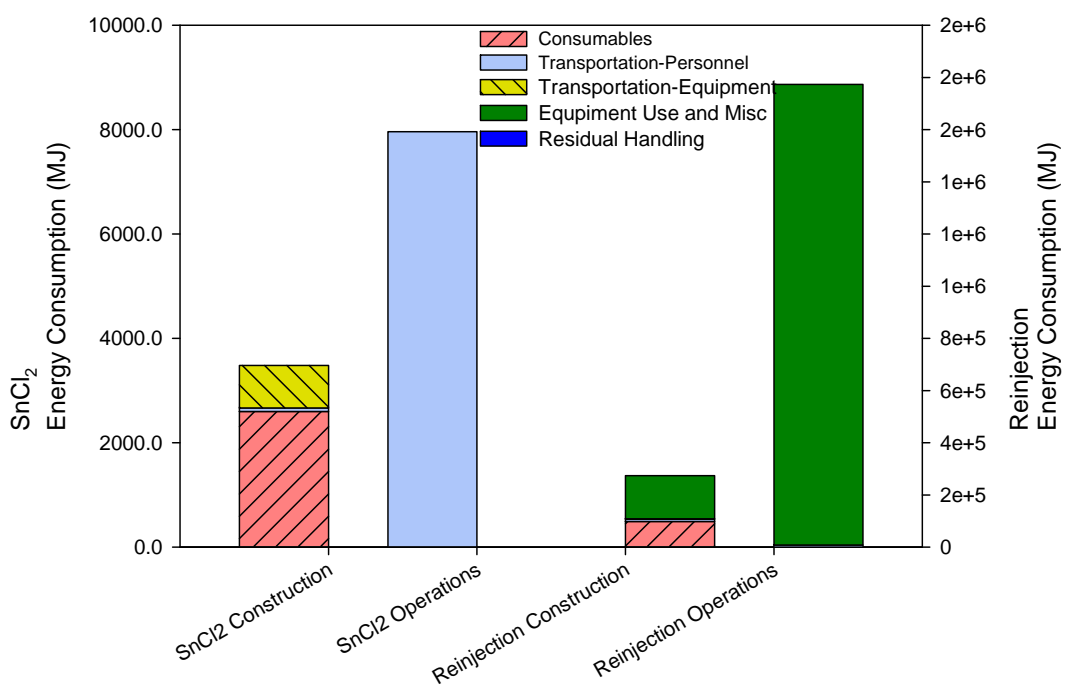

Figure 3. Energy consumption results for SW for A/M Area. Note different scales for SnCl2 and Reinjection. 


\subsection{Tool Comparison}

SW is more dependent upon knowledge of equipment and materials used, while SRT is more dependent on remediation theory and contaminants present. This is reflected both in the inputs and outputs for the two tools. SRT requires a description of the contaminated area: concentrations and type of contaminant, plume dimensions, and soil and aquifer characteristics. SRT has two levels of project specificity: Tier 1 and Tier 2. Tier 1 utilizes default values for the remediation processes and requires less user-input data. Tier 2 requires more site-specific, user input and allows the software to more closely model the project. SW requires descriptions of processes: lengths of pipe, quantities of construction materials, equipment use based on rated power or flow, and includes some specific processes like excavation, drilling, and agricultural land treatment. SRT allows input for two project phases in three configurations: construction, operation, or construction/operation. SW allows input for four project phases: investigation, construction, operation, and long-term monitoring. The data requirements for SW are more extensive than those for SRT.

The outputs correspondingly reflect the different nature of the calculation processes for the two tools. SRT incorporates remediation models into its calculation, and thus includes plume characteristics and final contaminant masses for the site. This allows the tool to calculate costs for the project based on typical costs for the specific remediation process. A further optional output of SRT is the change natural resource service, a calculation of the monetary value of fresh water or land, associated with the remediation project. The input data were not available for the natural resource service, thus resource service was not calculated. The output consists of a table of values that is not differentiated between construction and operation unless calculated separately. The output tables from SRT could not be selected within Microsoft Excel, making working with the output more difficult than for SW.

SW breaks up the results into phases of the project life cycle and activity categories within each phase, and SRT does not; this difference allows the SW user to identify dominating factors for the impact categories easily. In general each impact category was dominated by its operation phase. In general the operation phase impacts were dominated by the operation of equipment connected to the electrical grid. Notable exceptions include risk of both accident and fatality which tend to be dominated by personnel transport during operations, occasionally with significant contributions from equipment use and personnel transportation in investigation and construction phases. Additionally, when the overall impacts of a process were small, particularly in energy consumption, personnel transportation during operations tended to dominate the impacts.

Water consumption was only calculated by SW and only as it applied to cooling water in electricity generation. Because water consumption was only tied to electricity generation, the results for water consumption were not explicitly presented in this report. Water was considered in SRT within the resource value calculations, but the required data were not available to include calculations of resource value in this study. SW does allow the user to input discrete quantities for the phases of the life cycle; however, this does not take into account the quality of the water or the replacement of water. For example, the reinjection system for $\mathrm{A} / \mathrm{M}$ area puts drinking-quality water back into the aquifer, while the $\mathrm{SnCl}_{2}$ system outputs the water to a surface stream. In order to assign those particular impacts, the air stripping system would need to be included, as it is the 
CVOC contamination, not the mercury contamination that required the withdrawal of the water in the first place. That particular consideration was beyond the scope of this study as the CVOC treatment in this area has a complex history with a number of treatment technologies that span multiple decades. This issue does highlight the problem of system boundaries and metrics within the broader field of quantifying sustainability.

By breaking up the impacts into phases and activities within phases, SW gives the user some insight into ways to reduce the impact of the project. While it is site protocol to physically inspect active projects daily to ensure proper function, the SW results suggest that reducing the number of visits to project sites could reduce the impact of projects. By ensuring that installed equipment does not exceed required specifications, the energy consumption could be reduced. SW results indicate that the energy mix can influence the impacts. Operating electrical equipment exclusively from a nuclear source could help avoid emissions of carbon, nitrogen, and sulfur; while operating at night could influence the energy mix without changing the energy supplier potentially with additional monetary savings associated with off-peak consumption.

The SRNL/DOE-SRI identified four goal categories to help achieve the best environmental quality from remediation projects: mitigating damages, maximizing environmental services, minimizing resource footprint, and managing risks. SRT addresses each of these goals to some extent. SW only addresses resource footprint and risk. Both tools treat only risk to workers associated with the cleanup effort. Neither tool considers the risk to the community from the contaminant or the balance between worker and community risk. Neither tool considered the risk of contaminant transfer from one medium to another medium. Because SRT does include mitigating damage-a calculation of how much contaminant remains after remediation-its available treatment options are limited to the processes those that are modeled in the software. As previously mentioned, SRT's inclusion of environmental services impacts could not be included in this study due to lack of data. The primary focus of both tools is the resource footprint associated with the remediation effort.

Because of its dependence on specific models of remediation and its inclusion of mitigation of damages, SRT could not accommodate novel methods; if the contaminant or approach was not included in the software, then the software could not generate meaningful results. SW was more flexible because it did not require knowledge of the contaminant or the nature of the technique. SW required knowledge of equipment specifics, and it was able to accommodate analysis of case studies where equipment specifics were documented, regardless of the contaminant and medium. This study suggests that SW would be the easier of the two to adapt to novel remediation approaches or uncommon contaminants as long as information regarding the equipment, construction processes, and operational parameters were available. In the case of "traditional" contaminants and processes under consideration early in a project, SRT would be better suited to address issues of project sustainability, as equipment and operation specifics would not likely be available yet.

\subsection{Conclusions}

This study examined two sustainable remediation software tools using case studies of projects at SRS and combined retrospective analysis and prospective analysis of different 
treatment options at the various sites. It is reasonable to wonder if this study represents a fair evaluation of these two software packages, as they were used outside of the scope explicitly stated in their documentation: both were designed for implementation during planning stages of a remediation project. However, pushing the edge of the software suitability revealed information useful to project planners: if the project is considering traditional organic contaminants in conventional media: CVOCs or total benzenetoluene-ethylbenzene-xylene (BTEX) in soil or groundwater and project planning is in its early phases, SRT is likely to be more useful, as equipment requirements are not likely to be known yet. If the project has progressed to the stage of planning for equipment and construction or if the project considers contaminants other than CVOCs or total BTEX, SiteWise is likely to yield results more relevant to that particular project. In addition SiteWise would be able to identify phases and activities that dominate the environmental impacts.

Future work regarding these two tools could include calculating the mass of CVOCs treated at TNX in the groundwater and soil to compare SRT's predictions to the actual project progress. Further, a deliberate attempt to bring the results of SRT and SW into agreement could increase confidence in the tools. For H-12 outfall, using LCA software to calculate impacts of humate and peat rather than hand calculations is another potential avenue of further work. Designing an ion exchange system for $\mathrm{H}-12$ would allow comparison of innovative remediation methods to more traditional methods.

The results of this study and the considerations necessary to qualify some of those results, particularly water consumption, highlight the importance of the decision maker in the implementation of sustainability strategies. It is ultimately the decision maker who decides how to weight the individual impact categories and how to include qualitative information.

This project will be/has been presented in part at the International Symposium on Bioremediation and Sustainable Environmental Technologies June 27-30, 2011 in Reno, NV. The abstract and proceedings paper associated with this presentation are attached as Appendices 1 and 2 respectively.

\subsection{References}

Halverson, N.V., B.B. Looney, M.R. Millings, R.L. Nichols, and J.V. Noonkester (2010). Detoxification of Outfall Water Using Natural Organic Matter. SRNL-STI-201000418, Aiken, SC, Savannah River National Laboratory.

Looney, B.B., M.E. Denham, and K.M. Vangelas (2001). Ultralow Concentration Mercury Treatment Using Chemical Reduction and Air Stripping. WSRC- MS-200100388, Aiken, SC, Westinghouse Savannah River Company.

Looney, B.B., D.G. Jackson, M.J. Peterson, T.J. Mathews, G. Southworth, L. Bryan, M. Paller, C. Eddy-Eilek, N.V. Halverson (2010). Assessing Potential Impacts of Stannous Chloride Based Mercury Treatment on a Receiving Stream Using RealWorld Data from Tims Branch, Savannah River Site. SRNL-STI-2010-00393, Aiken, SC, Savannah River National Laboratory. 
Looney, B.B. and M. R. Millings (2009). Development of Process Control Equations to Support Detoxification of Copper using Natural Humate Amendments. SRNL-STI2009-00353, Aiken, SC, Savannah River National Laboratory.

Millings, M.R., B.B. Looney, N.V. Halverson, and R.L. Nichols (2008). Detoxification of Copper in Surface Water Discharge Using Soluble Humic Acid Amendment: Technical Summary of Results. WRSC-STI-2008-00105, Aiken, SC, Savannah River National Laboratory.

Nichols, R.L. (2010). Re: Sustainable Remediation Initiative. SRNL-L6200-2009-0008, Aiken, SC, Savannah River National Laboratory.

Noonkester, J.V., R.L. Nichols, and K.L. Dixon (2005). Innovative Technologies and Vadose Zone Treatment of Chlorinated Volatile Organic Compounds - Case Study. WSRC-MS-2005-00048, Aiken, SC, Savannah River National Laboratory.

Riha, B.D., B.B. Looney, M. Denham, K. Bagwell, R. Hall, and C. Eddy-Dilek (2006). Studies to Support Deployment of Edible Oils as the Final cVOC Remediation in TArea: Summary Report. WSRC-TR-2006-00363, Aiken, SC, Savannah River National Laboratory.

Riha, B.D., B.B. Looney, J.V. Noonkester, and K. Hyde (2009). Treatability Study for Edible Oil Deployment for Enhanced cVOC Attenuation for T-Area, Savannah River Site: Interim Report - Year One. SRNL-RP-2009-00539, Aiken, SC, Savannah River National Laboratory.

Riha, B.D., B.B. Looney, J.V. Noonkester, K. Hyde, R. Walker, and B. Rambo. (2010). Treatability Study for Edible Oil Deployment for Enhanced cVOC Attenuation for TArea, Savannah River Site: Interim Report - Year Two. SRNL-RP-2010-01029, Aiken, SC, Savannah River National Laboratory.

WSRC (2007). H-Material Disposition Area Project: H-12 NPDES Outfall Corrective Action Alternatives Study (U). WRSC-RP-2007-4016, Aiken, SC, Washington Savannah River Company. 


\author{
Appendix 1 \\ Presentation Abstract \\ Battelle: Bioremediation and Sustainable Environmental \\ Technologies Symposium \\ June 27-30, 2011 \\ Reno, NV \\ Session: E1. Estimating Remediation Impacts: \\ Tools and Approaches
}




\title{
Sustainable Remediation Software Tool Exercise and Evaluation
}

\author{
Joel L. Kohn (joel.kohn@srs.gov) (South Carolina Universities Research and Education \\ Foundation / Savannah River National Laboratory, Aiken, South Carolina, USA) \\ Ralph L. Nichols and Brian B. Looney (Savannah River National Laboratory, Aiken, South \\ Carolina, USA)
}

Background/Objectives. To advance the acceptance and incorporation of green and sustainable remediation metrics into the larger body of remedial work, the Center for Sustainable Groundwater and Soil Solutions (CSGSS) within the Savannah River National Laboratory (SNRL) created the Sustainable Remediation Initiative (SRI). The goals of SRI are to mitigate damages, maximize environmental services, minimize remediation resource footprint, and manage risks associated with remedial actions. Software tools can play an important role in the selection of a remedial alternative based on the above goals. The objective of this project was to exercise and evaluate two existing software packages designed to account for some of the above goals.

Approach. The Savannah River Site near Aiken, SC, has a unique opportunity to study sustainable approaches to remediation with its large number of remediation efforts, documented procedures, and a mix of traditional and innovative treatment regimens. To this end, three case studies of completed or ongoing remediation projects were selected to compare and contrast the results from two existing software packages: SiteWise and Sustainable Remediation Tool (SRT). These packages were developed by various military entities and a private company for use in the planning phase of a remedial operation to quantify the environmental footprint of a given alternative and to help identify the tradeoffs associated with the alternatives, similar to Life Cycle Assessment. The three case provided variety both in contaminant and in contaminated medium. These ranged from a classic remediation problem of chlorinated volatile organic compounds (CVOCs) in groundwater and soil, to a non-traditional problem of surface water contaminated with dissolved copper.

For each case study, a variety of treatment options had been considered on-site. The implemented solution's supporting documents and engineering plans provided the input data for the software packages as a base scenario. This base scenario was then compared to alternatives that were not implemented, for which data were not as readily available. The necessary data for these other options were derived from project proposals, similar actions elsewhere on site, and rules of thumb. The results of the software runs were used to compare and contrast the software packages and to evaluate the software based on the goals of the SRI.

Results. SiteWise proved to be the more flexible of the tools; it allowed the input of non-traditional remedial activities. However, this flexibility came at the cost of requiring more specific input data than SRT. SRT contained models of specific treatment technologies, which made the package more amenable to data-limited situations. The flexibility of SiteWise was highlighted by the Cu-surface water case study in that both contaminant and contaminated medium were not included in SRT's models. This flexibility was also an advantage for SiteWise in modeling mercury-groundwater case study alternatives. The final case study of CVOC-groundwater started the tools on more equal footing, and the results of the two programs were generally within an order of magnitude of each other for the six impact categories that the programs shared. Both tools addressed the SRI goals of minimizing footprint and managing risks by calculating those values, but not all of the goals were addressed by both programs. Although the tools were used partially outside of their intended scope, this study showed that the tools were useful for comparing remedial alternatives and can play an important role in the proliferation of green and sustainable remediation. 
Appendix 2

Proceedings Paper

Battelle: Bioremediation and Sustainable Environmental Technologies Symposium

June 27-30, 2011

Reno, NV

Session: E1. Estimating Remediation Impacts:

Tools and Approaches 


\title{
Sustainable Remediation Software Tool Exercise and Evaluation
}

\author{
Joel L. Kohn (joel.kohn@srs.gov) (South Carolina Universities Research and Education \\ Foundation / Savannah River National Laboratory, Aiken, South Carolina, USA) \\ Ralph L. Nichols and Brian B. Looney (Savannah River National Laboratory, Aiken, \\ South Carolina, USA)
}

\begin{abstract}
The goal of this study was to examine two different software tools designed to account for the environmental impacts of remediation projects. Three case studies from the Savannah River Site (SRS) near Aiken, SC were used to exercise SiteWise (SW) and Sustainable Remediation Tool (SRT) by including both traditional and novel remediation techniques, contaminants, and contaminated media. This study combined retrospective analysis of implemented projects with prospective analysis of options that were not implemented. Input data were derived from engineering plans, project reports, and planning documents with a few factors supplied from calculations based on Life Cycle Assessment (LCA). Conclusions drawn from software output were generally consistent within a tool; both tools identified the same remediation options as the "best" for a given site. Magnitudes of impacts varied between the two tools, and it was not always possible to identify the source of the disagreement. The tools differed in their quantitative approaches: SRT based impacts on specific contaminants, media, and site geometry and modeled contaminant removal. SW based impacts on processes and equipment instead of chemical modeling. While SW was able to handle greater variety in remediation scenarios, it did not include a measure of the effectiveness of the scenario.
\end{abstract}

\section{INTRODUCTION}

There is a growing awareness of the importance of sustainable solutions for continued human existence. It is within this awareness that the Center for Sustainable Groundwater and Soil Solutions within the Savannah River National Laboratory (SRNL) and the larger U.S. Department of Energy (DOE) created the Sustainable Remediation Initiative (SRI) (Nichols, 2010) to advance the acceptance and incorporation of green and sustainable remediation metrics into the larger body of remediation work. A further goal of the SRI is to increase awareness of the availability of novel remediation techniques and tools. Specifically the SRI aims to achieve the best possible environmental quality by focusing on four goal categories: mitigating damages, maximizing environmental services, minimizing remediation resource footprint, and managing risks.

Expanding the scope of remediation projects beyond the traditional emphasis on simply mitigating damages makes the selection of the "best" alternative more complicated. Software tools can thus play an important role in the identification and selection of the ideal remediation technology for a given project. To this end, sustainable remediation software tools are available to treat the remediation process with a method similar to LCA by considering environmental impacts from different phases of a remediation project. These tools take into account the energy inputs and emission outputs associated with manufacturing materials and chemicals, construction processes, and continued operation and maintenance of the remediation project. 
This project focused on two existing software tools designed to approach sustainable remediation. The tools themselves are both based on the Microsoft Excel spreadsheet application and calculate impacts from user input combined with impact factors contained within the spreadsheet. SiteWise, final version, (SW) was developed by Battelle, the U.S. Navy, and the U.S. Army Corps of Engineers. Sustainable Remediation Tool, rev. 2, (SRT) was developed for the U.S. Air Force Center for Engineering and the Environment. They are both designed to be implemented in the planning stages of a project to estimate the environmental impacts of that project using different treatment technologies.

It was the goal of this study to exercise and evaluate two existing sustainable remediation software packages: SW and SRT by using two case studies of completed and ongoing remediation projects on the Savannah River Site (SRS).

Case Studies. SRS offers a unique opportunity to study sustainable approaches to remediation with a variety of remediation efforts, documented procedures, and a mix of traditional and innovative treatment regimens. Three case studies were selected to exercise SW and SRT, because of their mix of traditional approaches like pump-and-treat for Chlorinated Volatile Organic Compounds (CVOCs) and novel techniques like addition of a humate solution to detoxify copper. Selected results from two of those case studies, TNX area and H-12 outfall, are presented in this report to illustrate key aspects of the study.

TNX area was the site of pilot-scale testing of chemical processes to be used elsewhere on SRS. Non-radioactive waste was disposed in unlined basins which resulted in the contamination of the vadose zone and shallow groundwater with CVOCs. To treat the contaminants, a pump-and-treat system with air stripping was used for 10 years to immobilize the contaminant plume, while soil vapor extraction was used for a year to treat the source in the soil. The pump-and-treat system was followed by treatment with edible oil pumped into the aquifer as a final treatment to stimulate microbial activity to further degrade the CVOCs in the groundwater. (Riha et al., 2006; Riha et al., 2009; Riha et al., 2010; Noonkester et al., 2005)

The H-12 outfall serves as a discharge point for process water and surface runoff associated with H-Area of SRS. This discharge is in governed by a National Pollutant Discharge Elimination System (NPDES) permit that regulates the copper and zinc concentrations to $6 \mathrm{ppb}$ and $100 \mathrm{ppb}$ respectively. The copper concentration could not consistently meet the NPDES limit without treatment. The copper in this surface water can be attributed to copper components in plumbing and pumps, natural levels in groundwater withdrawn for processes, and storm water flow over impervious surfaces.

To bring this outfall into compliance with the NPDES permit, a variety of options were subjected to a feasibility study to identify cost effective treatments that would effectively mitigate the damage. The study identified peat beds as the best treatment technology beating out ion exchange, constructed wetland treatment, and water re-routing without treatment. Using a peat bed as a natural ion-exchange resin would have been a novel approach; however, before this treatment plan was implemented, another nontraditional option was identified: the injection of humate solution-naturally occurring organic matter-into the surface water to detoxify the copper rather than to remove it from the stream. The humate system was installed and consists of two 5500 gallon 
storage tanks for the liquid humate solution, pumps, a computer controller, and piping. The system is actively monitored, with sensors in the stream relaying information to the computer which regulates the metering pumps based on stream flow and $\mathrm{pH}$ (Looney and Millings, 2009; Halverson et al., 2010; Millings et al., 2009; WRSC, 2007).

\section{METHODS}

The software packages SiteWise and Sustainable Remediation Tool-Tier 2 were used to estimate the environmental impacts associated with a particular remediation project. The results were based on input data supplied by the user and on software-specific calculations to translate the quantities of materials, use of equipment and vehicles, and use of energy into impacts. Both SW and SRT require similar, but not identical inputs. These differences and their implications will be described further in the Results and Discussion section.

Input data were primarily derived from site reports and engineering drawings detailing the construction and operation of the various remediation operations. These included lengths and materials for pipes and wells, earth volumes for trenching, excavation, and other earthworks, and quantities of other materials for construction; times and schedules for investigation; treatment schedules, pumping rates and volumes, and visits by workers for operations; and follow-up monitoring schedules. Details of contaminant plume geometry and concentrations were also taken from site reports. Each active treatment required daily monitoring to ensure equipment operation. These data, where relevant, were entered into SRT and SW to generate the environmental impact for several categories: greenhouse gas (GHG) emissions, Energy consumption, water use, oxides of nitrogen (NOx) emissions, oxides of sulfur (SOx) emissions, coarse particulate matter $\left(\mathrm{PM}_{10}\right)$ emissions, fatality risk, accident risk, lost work hours and technology cost. Table 1 shows selected input and output from the two software packages.

Appendix 2 Table 1 Selected input and output from SW and SRT.

\begin{tabular}{|c|c|c|c|c|c|c|}
\hline & \multicolumn{4}{|c|}{ TNX Area } & \multicolumn{2}{|c|}{ H-12 NPDES Outfall } \\
\hline & $\begin{array}{l}\text { Soil Vapor } \\
\text { Extraction }\end{array}$ & Excavation & Pump \& Treat & Oil Injection & Humate Injection & Peat Beds \\
\hline $\begin{array}{l}\text { Quantity of media } \\
\text { treated }\end{array}$ & \multicolumn{2}{|c|}{$23,500 \mathrm{~m}^{3}$ soil } & \multicolumn{2}{|c|}{ 3.50E8 gal (1.32E9 L) groundwater } & \multicolumn{2}{|c|}{$\begin{array}{c}\text { 1.10E10 gal (4.18E10 L) waste water } \\
\text { discharge }\end{array}$} \\
\hline $\begin{array}{ll}\begin{array}{l}\text { Quantity } \\
\text { contaminant } \\
\text { treated }\end{array} & \begin{array}{l}\text { of } \\
\text { of }\end{array} \\
\end{array}$ & \multicolumn{2}{|c|}{$1.88 \mathrm{~kg}$ CVOCs } & \multicolumn{2}{|c|}{$66.1 \mathrm{~kg}$ CVOCs } & \multicolumn{2}{|c|}{320 kg copper } \\
\hline $\begin{array}{ll}\begin{array}{l}\text { Time } \\
\text { analyzed }\end{array} & \text { frame } \\
\end{array}$ & $1 \mathrm{yr}$ & na & $\begin{array}{l}10 \mathrm{yr}(95 \% \\
\text { operation) }\end{array}$ & $5 \mathrm{yr}$ & $30 \mathrm{yr}$ & $30 \mathrm{yr}$ \\
\hline $\begin{array}{l}\text { Primary equipment/ } \\
\text { components }\end{array}$ & 1x 15hp pump & $\begin{array}{l}23,500 \mathrm{~m}^{3} \text { removed } \\
\text { and backfilled }\end{array}$ & $\begin{array}{c}4 \times 3 \mathrm{hp} \mathrm{gw} \\
\text { pumps, one air } \\
\text { stripper (2x 5hp } \\
\text { blower) }\end{array}$ & $\begin{array}{c}1 \times \text { high-head } \\
\text { variable rate pump, } \\
5.30 \mathrm{E} 4 \mathrm{lb}(2.40 \mathrm{E} 4 \\
\mathrm{kg}) \text { oil } \\
\end{array}$ & $\begin{array}{c}\text { 1x.75hp, } 2 \times 3 \mathrm{hp} \\
\text { pumps } \\
\text { 4.68E6 gal (1.77E7 } \\
\text { L) Humate } \\
\end{array}$ & $\begin{array}{c}4 \times 815 \mathrm{gpm}, 20 \\
\mathrm{ft} \text { head pump, } \\
5.55 \mathrm{E} 6 \mathrm{~kg} \text { peat }\end{array}$ \\
\hline $\begin{array}{l}\text { Energy } \\
\text { Consumption, MJ } \\
\text { (SWISRT) }\end{array}$ & 1.11E6 / 3.9E5 & 2.58E6 / 5.10E6 & 1.60E7 / 7.70E6 & 2.53E5 / 2.70E4 & 18.5E6 / na & $1.94 \mathrm{E} 7 / \mathrm{na}$ \\
\hline $\begin{array}{l}\text { Greenhouse gas } \\
\text { emissions, metric } \\
\text { ton (SWISRT) }\end{array}$ & $69.3 / 24.5$ & $140 / 354$ & $1020 / 426$ & $11.0 / 66.2$ & $1,140 /$ na & $1,120 /$ na \\
\hline $\begin{array}{l}\mathrm{NO}_{\mathrm{x}} \text { metric ton } \\
\text { (SWISRT) }\end{array}$ & 9.75E-2 / 1.36E-1 & $0.347 / 2.81$ & $1.71 / 2.54$ & 3.94E-3 / 1.45E-2 & $1.28 / \mathrm{na}$ & $1.20 / \mathrm{na}$ \\
\hline $\begin{array}{l}\text { SO }_{\mathrm{X}} \text { metric ton } \\
\text { (SWISRT) }\end{array}$ & $0.396 / 0.227$ & 8.48E-2 / 0.0272E-2 & $5.33 / 4.72$ & 1.43E-2 / 4.08E-3 & $5.34 / \mathrm{na}$ & $3.29 / \mathrm{na}$ \\
\hline $\begin{array}{l}\mathrm{PM}_{10} \text { metric ton } \\
\text { (SWISRT) }\end{array}$ & $5.38 \mathrm{E}-4 / 4.08 \mathrm{E}-2$ & $3.55 \mathrm{E}-2$ / 1.36 & $0.0382 / 0.880$ & $1.81 \mathrm{E}-3 / 7.26 \mathrm{E}-4$ & $6.17 \mathrm{E}-3 / \mathrm{na}$ & $4.54 \mathrm{E}-2$ / na \\
\hline $\begin{array}{ll}\begin{array}{l}\text { Injury } \\
\text { (SWISRT) }\end{array} & \text { Risk } \\
\end{array}$ & $5.21 \mathrm{E}-3 / 1.60 \mathrm{E}-3$ & $0.0399 / 0.200$ & 3.60E-2 / 1.40E-2 & $5.57 \mathrm{E}-4 / 4.20 \mathrm{E}-4$ & $2.24 \mathrm{E}-2$ / na & $7.70 \mathrm{E}-2$ / na \\
\hline
\end{tabular}




\section{RESULTS AND DISCUSSION}

The results of SW are a series of bar-charts based on the output of each remediation option for each impact category and are also subdivided into impacts associated with each phase of each project. There is one chart for each impact category: greenhouse gas (GHG) emissions, energy consumption, water impacts, $\mathrm{NO}_{\mathrm{x}}$ emissions, $\mathrm{SO}_{\mathrm{x}}$ emissions, coarse particulate matter $\left(\mathrm{PM}_{10}\right)$, risk of fatality, and risk of injury. These results are further subdivided into a page for each remediation alternative where each phase of the project-investigation, construction, operation, and long-term monitoring-is represented by a bar that is divided into sections based on the contribution to the total impact for the phase by five categories: consumables (materials), personnel transportation, equipment transportation, equipment use, and residual handling.

The results of SRT consist of a table of values of environmental impacts for several categories. The impact categories in SRT are carbon dioxide emissions, $\mathrm{NO}_{\mathrm{x}}$ emissions, $\mathrm{SO}_{\mathrm{x}}$ emissions, coarse particulate matter $\left(\mathrm{PM}_{10}\right)$, energy consumption, technology cost, safety/accident risk, and change in resource service.

TNX. Both SW and SRT were used to analyze soil and groundwater remediation actions for TNX. The actions analyzed for contaminated soil were soil vapor extraction and excavation. SVE consisted of one year of treatment followed by four years of continued monitoring. Excavation (not implemented) consisted of three months of excavating the contaminated soil, transporting it to a hazardous waste disposal unit, and transporting clean fill to the site. Figure 1 shows selected results for the different tools and different remediation actions for both soil and groundwater at TNX. Soil vapor extraction was determined to have lower greenhouse gas emissions, energy consumption, NOx emissions and injury risk than excavation by both SW and SRT.

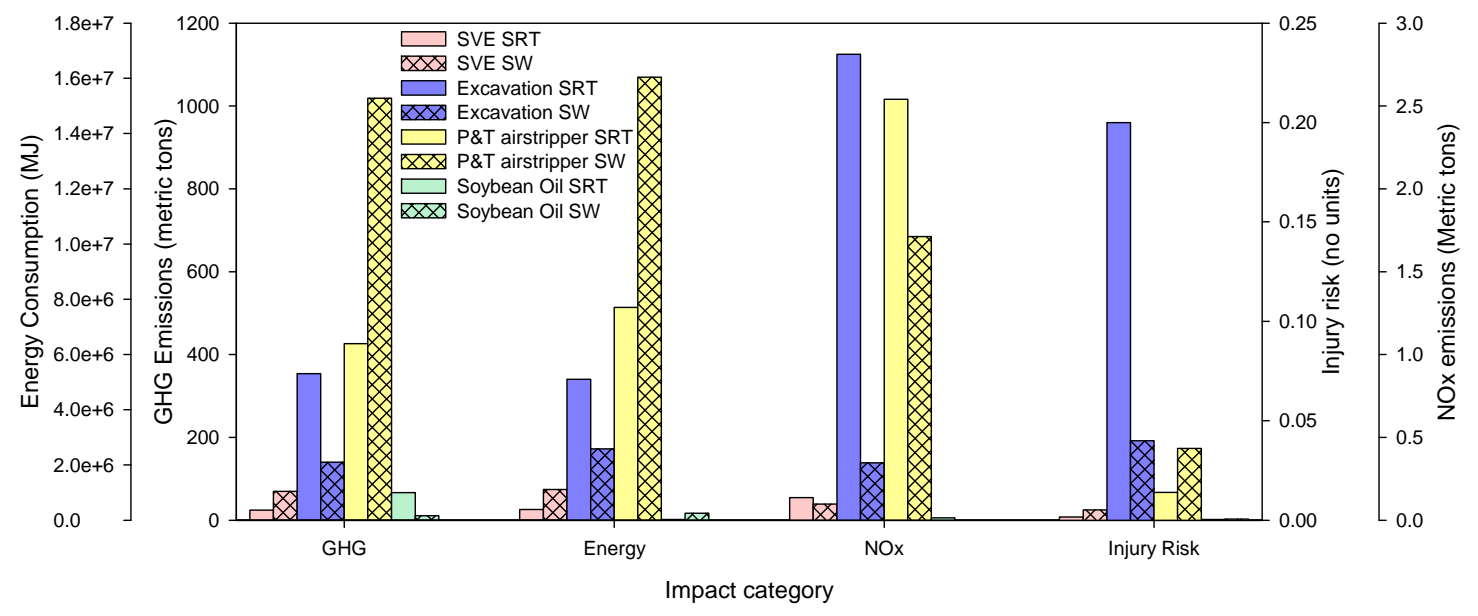

Appendix 2 Figure 1. Selected impact category results for TNX area. Note multiple scales.

The groundwater remediation strategy was to contain contaminated groundwater while a final action was identified. A pump and treat system with air stripping for containment was operated for ten years prior to the use of oil injection for mass removal in the heart of the contaminant plume. Long-term monitoring was included with the oil 
treatment in this analysis rather than with the pump-and-treat system. The oil injection included 60 days of oil injection spread over 1 year followed by 4 years of quarterly monitoring. Energy consumption and injury risk from SW were higher than SRT for both pump and treat and oil injection, while SRT had higher estimates than SW for NOx emissions in both scenarios.

H-12. Peat beads and humate injection for meeting NPDES limits at the H12 Outfall were analyzed using SW only; the considered scenarios incompatible with SRT input structure required. SW breaks remediation actions into phases and the activities necessary to complete the phases. For purposes of this analysis the treatment time was assumed to be 30 years. Thirty years was chosen as a reasonable estimate of SRS operations in the area, and captures 6 replacement cycles of the peat cell system. Replacement every 5 years for the peat system was a conservative estimate based on preliminary reports and was designed to prevent accumulation of radioisotopes in the peat to a level which would require its disposal as a mixed waste. Figure 2 presents a breakdown of energy consumption by activity for both the construction and operation phase of both actions analyzed for $\mathrm{H}-12$.

During construction of both alternatives consumables represent the largest energy demand while during operation equipment use dominated energy consumption.

The impacts for the humate system were dominated by the use of electric pumps to recirculate and inject the humate solution into the stream. These pumps run constantly, and even though they are controlled by a computer system, the required amendment volume is typically below the minimum operational speed for the pumps.

SW does not incorporate the impact of clearing, grubbing, and disposition of waste from approximately three acres of woodland that would have been required for the construction of the peat beds, and these impacts were not manually estimated. The humate system did have

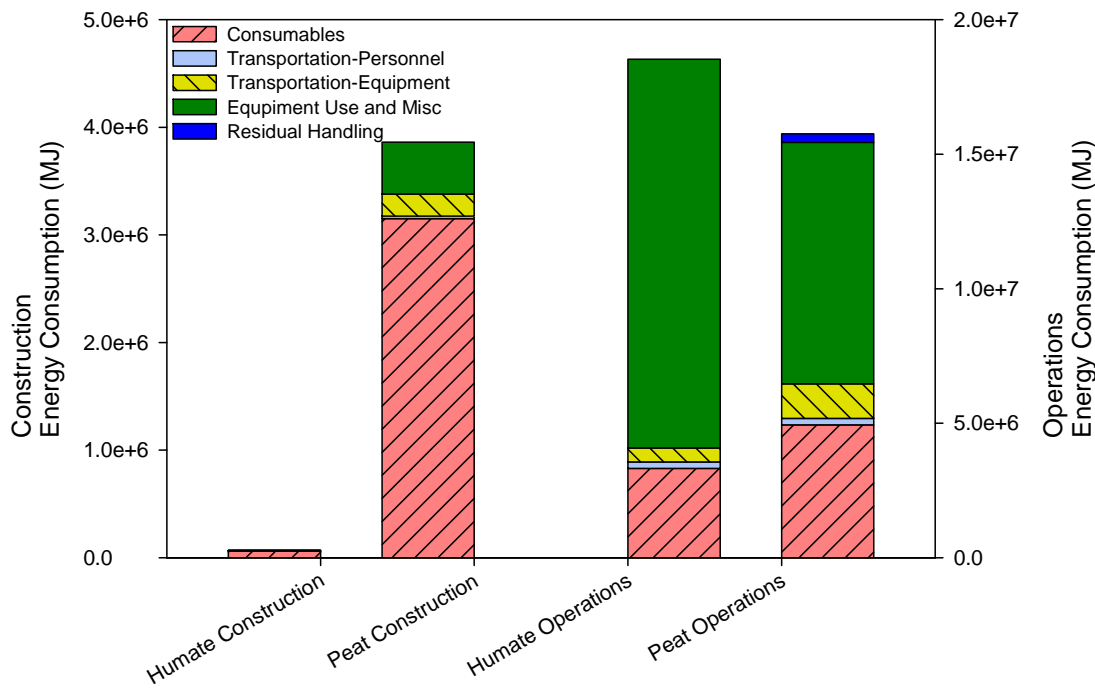
significantly less construction associated with it, and this is partially reflected in the difference in the

Appendix 2 Figure 2. H-12 outfall energy consumption results from SRT broken down by operative phase and activity. Note different scales. risk to the workers at this site. 
Tool Comparison. SW is more dependent on knowledge of equipment and materials used, while SRT is more dependent on remediation theory and contaminants present. This is reflected both in the inputs and outputs for the two tools. SRT requires a description of the contaminated area: concentrations and type of contaminant, plume dimensions, and soil and aquifer characteristics. SRT has two levels of project specificity: Tier 1 and Tier 2. Tier 1 utilizes default values for the remediation processes and requires less user-input data. Tier 2 requires more site-specific, user input and allows the software to more closely model the project. SW requires descriptions of processes: lengths of pipe, quantities of construction materials, equipment use based on rated power or flow, and includes some specific processes like excavation, drilling, and agricultural land treatment. SRT allows input for two project phases in three configurations: construction, operation, or construction and operation. SW allows input for four project phases: investigation, construction, operation, and long-term monitoring. The data requirements for SW are more extensive than those for SRT.

The outputs correspondingly reflect the different nature of the calculation processes for the two tools. SRT incorporates remediation models into its calculation, and thus includes plume characteristics and final contaminant masses for the site. This allows the tool to calculate costs for the project based on typical costs for the specific remediation process. A further optional output of SRT is the change natural resource service, a calculation of the monetary value of fresh water or land, associated with the remediation project. The input data were not available for the natural resource service, thus resource service was not calculated. The output consists of a table of values that is not differentiated between construction and operation unless calculated separately. The output tables from SRT could not be selected within Microsoft Excel, making working with the output more difficult than for SW.

SW breaks up the results into phases of the project life cycle and activity categories within each phase, and SRT does not; this difference allows the SW user to identify dominating factors for the impact categories easily. In general each impact category was dominated by its operation phase. In general the operation phase impacts were dominated by the operation of equipment connected to the electrical grid. Notable exceptions include risk of both accident and fatality which tend to be dominated by personnel transport during operations, occasionally with significant contributions from equipment use and personnel transportation in investigation and construction phases. Additionally, when the overall impacts of a process were small, particularly in energy consumption, personnel transportation during operations tended to dominate the impacts.

By breaking up the impacts into phases and activities within phases, SW gives the user some insight into ways to reduce the impact of the project. While it is site protocol to physically inspect active projects daily to ensure proper function, the SW results suggest that reducing the number of visits to project sites could reduce the impact of projects. By ensuring that installed equipment does not exceed required specifications, the energy consumption could be reduced. SW results indicate that the energy mix can influence the impacts. Operating electrical equipment exclusively from a nuclear source could help avoid emissions of carbon, nitrogen, and sulfur; while operating at night could influence the energy mix without changing the energy supplier and could offer monetary savings with off-peak consumption. 
The SRNL/DOE-SRI identified four goal categories to help achieve the best environmental quality from remediation projects: mitigating damages, maximizing environmental services, minimizing resource footprint, and managing risks. SRT addresses each of these goals to some extent. SW only addresses resource footprint and risk. Both tools treat only risk to workers associated with the cleanup effort. Neither tool considers the risk to the community from the contaminant or the balance between worker and community risk. Because SRT does include mitigating damage-a calculation of how much contaminant remains after remediation-its available treatment options are limited to the processes those that are modeled in the software. As previously mentioned, SRT's inclusion of environmental services impacts could not be included in this study do to lack of data. The primary focus of both tools is the resource footprint associated with the remediation effort.

Because of its dependence on specific models of remediation and its inclusion of mitigation of damages, SRT could not accommodate novel methods; if the contaminant or approach was not included in the software, then the software could not generate meaningful results. SW was more flexible because it did not require knowledge of the contaminant or the nature of the technique. SW required knowledge of equipment specifics, and it was able to accommodate analysis of case studies where equipment specifics were documented, regardless of the contaminant and medium. This study suggests that SW would be the easier of the two to adapt to novel remediation approaches or uncommon contaminants as long as information regarding the equipment, construction processes, and operational parameters were available. In the case of "traditional" contaminants and processes under consideration early in a project, SRT would be better suited to address issues of project sustainability, as equipment and operation specifics would not likely be available yet.

\section{CONCLUSIONS}

This study examined two sustainable remediation software tools using case studies of projects at SRS and combined retrospective analysis and prospective analysis of different treatment options at the various sites. It is reasonable to wonder if this study represents a fair evaluation of these two software packages, as they were used outside of the scope explicitly stated in their documentation: both were designed for implementation during planning stages of a remediation project. However, pushing the edge of the software suitability revealed information useful to project planners: if the project is considering traditional organic contaminants in conventional media: CVOCs or total benzenetoluene-ethylbenzene-xylene (BTEX) in soil or groundwater and project planning is in its early phases, SRT is likely to be more useful, as equipment requirements are not likely to be known yet. If the project has progressed to the stage of planning for equipment and construction or if the project considers contaminants other than CVOCs or total BTEX, SiteWise is likely to yield results more relevant to that particular project. In addition SiteWise would be able to identify phases and activities that dominate the environmental impacts.

Future work regarding these two tools could include calculating the mass of CVOCs treated at TNX in the groundwater and soil to compare SRT's predictions to the actual project progress. Further, a deliberate attempt to bring the results of SRT and SW into agreement could increase confidence in the tools. For H-12 outfall, using LCA software 
to calculate impacts of humate and peat rather than hand calculations is another potential avenue of further work. Designing an ion exchange system for $\mathrm{H}-12$ would allow comparison of innovative remediation methods to more traditional methods.

\section{ACKNOWLEDGEMENTS}

This work was funded by the Center for Sustainable Groundwater and Soils Solutions which is managed by the Savannah River National Laboratory for the US Department of Energy Office of Environmental Management.

\section{REFERENCES}

Halverson, N.V., B.B. Looney, M.R. Millings, R.L. Nichols, and J.V. Noonkester. 2010. Detoxification of Outfall Water Using Natural Organic Matter. Technical Report SRNL-STI-2010-00418. Savannah River National Laboratory, Aiken, SC.

Looney, B.B. and M.R. Millings. 2009. Development of Process Control Equations to Support Detoxification of Copper using Natural Humate Amendments. Technical Report SRNL-STI-2009-00353. Savannah River National Laboratory, Aiken, SC.

Millings, M.R., B.B. Looney, N.V. Halverson, and R.L. Nichols. 2008. Detoxification of Copper in Surface Water Discharge Using Soluble Humic Acid Amendment: Technical Summary of Results. Technical Report WRSC-STI-2008-00105. Savannah River National Laboratory, Aiken, SC.

Nichols, R. L. 2010. Re: Sustainable Remediation Initiative. Letter SRNL-L6200-20090008, Aiken, SC, Savannah River National Laboratory.

Noonkester, J.V., R.L. Nichols, and K.L. Dixon. 2005. Innovative Technologies and Vadose Zone Treatment of Chlorinated Volatile Organic Compounds - Case Study. Technical Report WSRC-MS-2005-00048. Savannah River National Laboratory, Aiken, SC.

Riha, B.D., B.B. Looney, M. Denham, K. Bagwell, R. Hall, and C. Eddy-Dilek. 2006. Studies to Support Deployment of Edible Oils as the Final cVOC Remediation in TArea: Summary Report. Technical Report WSRC-TR-2006-00363. Savannah River National Laboratory, Aiken, SC.

Riha, B.D., B.B. Looney, J.V. Noonkester, and K. Hyde. 2009. Treatability Study for Edible Oil Deployment for Enhanced cVOC Attenuation for T-Area, Savannah River Site: Interim Report - Year One. Technical Report SRNL-RP-2009-00539. Savannah River National Laboratory, Aiken, SC.

Riha, B.D., B.B. Looney, J.V. Noonkester, K. Hyde, R. Walker, and B. Rambo. 2010. Treatability Study for Edible Oil Deployment for Enhanced cVOC Attenuation for TArea, Savannah River Site: Interim Report - Year Two. Technical Report SRNL-RP2010-01029. Savannah River National Laboratory, Aiken, SC.

WSRC. 2007. H-Material Disposition Area Project: H-12 NPDES Outfall Corrective Action Alternatives Study (U). Technical Report WRSC-RP-2007-4016. Washington Savannah River Company, Aiken, SC. 


\section{Distribution:}

K. D. Gerdes, EM-32

G. M. Chamberlain Jr., EM-32

J. C. Griffin, 773-A

J. E. Marra, 773-A

R. S. Aylward, 773-42A

B. B. Looney, 773-42A

R. L. Nichols, 773-42A

K. M. Jerome, 773-42A

J. L. Kohn, 773-42A 